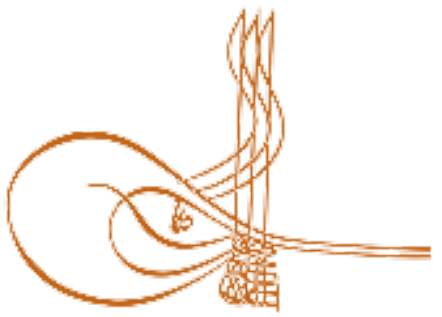

www.turkishstudies.net/education
Turkish Studies - Educational Sciences

eISSN: $2667-5609$

Research Article / Araştırma Makalesi

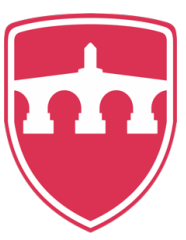

INTERNATIONAL

BALKAN

UNIVERSITY

Sponsored by IBU

\title{
Okuduğunu Anlama ve Yazılı Anlatım Becerileri Arasındaki İlişki: İlkokul Dördüncü Sinıflarda Bir İnceleme*
}

\author{
The Relationship between Reading Comprehension and Writing Skills: An Investigation on \\ Primary Fourth Year Students
}

\author{
Mustafa Yıldız $^{* *}$ - Gül Şebnem Altuner Çoban ${ }^{* * *}$ - Zehra Yaşar Sağlık ${ }^{* * *}$
}

\begin{abstract}
It is known that language skills are generally divided into two main areas: receptive and expressive language. Reading and listening/monitoring are expressed as receptive language skills based on understanding, and speaking and writing are expressed as expressive language skills based on narration. Although it is seen that reading is in comprehension-based language skills and writing is in narrative-based language skills in academic and functional language usage process; these two skills have a number of similar characteristics, such as the fact that they are basically written language skills and are based on formal education. Based on these similarities, the quality of the relationship between reading and writing skills paved the way for the study. In this context, the aim of the study is to investigate the relationship between reading and writing skills of fourth grade primary school students. The study group consisted of 141 fourth grade students attending 3 different primary schools in the city center of Kayseri during the fall semester of the 2018-2019 academic year. In the study group, easily accessible sampling method was used to speed up the research. "Reading Comprehension Test" developed by Kocaarslan (2015) was used to determine students' reading achievement levels and " $6+1$ Analytical Writing and Evaluation Scale" developed by Özkara (2007) was used to determine the writing success levels of the students. In this research, which is a correlational study designed in descriptive model, descriptive and predictive analyzes were used to determine the relationship between reading and writing skills of fourth grade students. The data were analyzed by using simple linear regression analysis for predicting
\end{abstract}

* Bu makale 16-20 Ekim 2019 tarihleri arasında yapılan 18. Uluslararası Sınıf Öğretmenliği Eğitimi Sempozyumunda sözlü bildiri olarak sunulmuştur. Araştırma verileri 2018-2019 eğitim-öğretim yılı güz döneminde toplanmıştır.

** Doç. Dr., Gazi Üniversitesi, Eğitim Fakültesi, Sınıf Eğitimi Anabilim Dalı

Assoc. Prof. Dr., Gazi University, Faculty of Education, Primary Education Department

ORCID 0000-0003-3885-5322

mustafa@gazi.edu.tr

*** Arş. Gör., Bozok Üniversitesi, Eğitim Fakültesi, Sınıf Eğitimi Anabilim Dalı

Res. Asst., Bozok University, Faculty of Education, Primary Education Department

ORCID 0000-0002-4508-571X

altunergulsebnem@gmail.com

**** Doktora Öğrencisi, Gazi Üniversitesi, Eğitim Bilimleri Enstitüsü, Sınıf Eğitimi Anabilim Dalı

PhD Student, Gazi University, Institute of Education Sciences, Primary Education Department

ORCID 0000-0001-5626-4660

zyasar1410@gmail.com

Cite as/ Atıf: Yıldız, M. \& Altuner Çoban, G. Ş. \& Yaşar Sağlık, Z. (2020). Okuduğunu anlama ve yazılı anlatım becerileri arasındaki ilişki, Turkish Studies - Education, 15(2), 1367-1379. https://dx.doi.org/10.29228/TurkishStudies.41891

Received/Geliş: 23 February/Şubat 2020

Accepted/Kabul: 27 April/Nisan 2020

Copyright $(\mathrm{INTAC}$ LTD, Turkey 
writing success by reading success and by using Pearson product-moment correlation coefficient to determine the relationship between reading success and writing success sub-dimensions. According to the results of the study, it was found that reading comprehension positively predicted writing skill and $35 \%$ of the total variance related to writing success was explained by reading success. On the other hand, students' writing success, ideas, style, word selection, sentence fluency, spelling and presentation dimensions were positively and moderately correlated with reading achievements; organization was found to be positively correlated and low level.

Structured Abstract: The main purpose of the communication forms and language activities that human beings have been in throughout his life; to understand any message read, listened, watched, and tell what is seen, heard and designed in the most clear and understandable way to those who are on the other side (Temizkan \& Sallabaş, 2009). Human beings can share their feelings, thoughts and desires with their environment thanks to this understanding and expression ability. These skills are basic language skills, reading and listening / watching are based on comprehension, and speaking and writing are narrative based on language skills. Every language in the world consists of these four basic principles. Regardless of what kind of language it is, where it comes from and how it is structured, all languages consist of reading, writing, speaking and listening skills (Yalçınkaya, Muluk \& Şahin, 2009). Reading and writing skills from the four basic language skills are the basic language skills to be acquired for our daily life and academic success. Both reading and writing are components of literacy. There is a general consensus that reading and writing skills complement each other. According to this consensus; reading and writing skills are basically written language skills, their teaching is carried out in an integrated manner, based on formal education. Due to this common view, the relationship between reading and writing skills has been the subject of several studies (Shanahan, 1984; Tierney and Shanahan, 1991; Uğur, 2018). Both theoretical and surveying, descriptive and intervening researches dealing with the relationship between reading and writing skills are quite abundant abroad. However, the existence of a limited number of studies addressing this relationship directly in Turkey (eg Uğur, 2017) and the examination of the relationship between basic language skills such as reading and writing, especially at elementary school level, constituted the reasons for our research.

\section{Purpose}

The aim of this research is to examine the relationship between reading and writing skills of primary school fourth grade students.

Sub-Purposes

For the purpose of the research, answers to the following research questions were sought:

- Is the reading comprehension skill of primary school fourth grade students a significant predictor of written expression skills?

- Are there any significant relationships between primary school fourth grade students' reading comprehension skills and writing skills sub-dimensions?

\section{Method}

\section{Research Method}

Researches in which the relationship between two or more variables is examined without any interference to these variables is called correlational studies (Neuman, 2006). This research is a correlational research designed in descriptive model because it examines the relationship between reading and writing skills of primary school fourth grade students.

\section{Research Group}

The study group of the research consisted of 141 fourth grade students, 77 of whom were girls (54.6\%) and 64 were boys (45.4\%), who were studying in primary schools in the city center of Kayseri during the 20182019 academic year. The study group was formed with an easily accessible sampling method for the purpose of the research. 


\section{Data Collecting Instruments}

"Reading Comprehension Test" developed by Kocaarslan (2015) and " $6+1$ Analytical Writing and Evaluation Scale" developed by Özkara (2007) were used to collect data on students' reading comprehension success.

\section{Data Collection Process}

The data collection process started with the collection of written expression data. In order to collect written expression data, students were asked to write a story by choosing any of the four topics determined by three domain experts. Written expression data were collected within one class hour in each class. After the story writing process has been completed, students have been given a reading comprehension test to collect reading comprehension data. The implementation of the test took two class hours in each class. After the students were informed about the test during the first lesson, the reading comprehension text was read once in the classroom as silent and once aloud. During the second lesson, questions about the reading comprehension test were answered by the students.

\section{Data Analysis}

"Simple linear regression analysis" was used to predict the success of writing by reading success. In determining the relationship between reading success and sub-dimensions of writing success, it was analyzed by using "pearson moments product correlation coefficient".

\section{Results}

The first sub-problem of the research is "Are primary school fourth grade students' reading comprehension skills a meaningful predictor of their writing skills?" It is stated as. According to the Simple Regression Analysis results for this sub-problem, the reading comprehension success positively predicted the success of writing $(\mathrm{R}=0.594, \mathrm{R} 2=0.35, \mathrm{~F}(1,139)=75,854, \mathrm{p}<.01)$ and it has been determined that $35 \%$ of the total variance related to writing success is explained with the success of reading comprehension. According to the results of the regression analysis, the regression equation related to the prediction of writing skill is "writing skill $=3.774+0.209$ reading comprehension".

The second sub-problem of the research is "Are there any significant relationships between the reading comprehension skills and writing skills sub-dimensions of the fourth grade students of primary school?" It is stated as. According to the Pearson Correlation test results for this sub-problem, students' writing success, ideas $(\mathrm{r}=0.423, \mathrm{p}<.01)$, style $(\mathrm{r}=0.465, \mathrm{p}<.01)$, word selection $(\mathrm{r}=0.356, \mathrm{p}<.01)$, sentence fluency $(\mathrm{r}=0.440, \mathrm{p}$ $<.01)$, spelling $(\mathrm{r}=0.498, \mathrm{p}<.01)$ and presentation $(\mathrm{r}=0.461, \mathrm{p}<.01)$ dimensions, positively and at medium level correlated with reading comprehension achievements where; organization $(r=0.260, p<.01)$ was found to be positively and at low level related.

\section{Conclusion}

According to the results of the research, it was determined that the success of reading comprehension predicted the success of writing positively and $35 \%$ of the total variance related to writing success was explained by the reading success. On the other hand, students' writing success is positively and at medium level correlated with reading achievements in the dimensions of ideas, style, word choice, sentence fluency, spelling and presentation; it was determined that it was positively and at a low level in organization dimension.

Keywords: Language Education, Reading, Writing, Reading and Writing Relationship, Primary School Students.

Öz: Dil becerilerinin, alıcı ve ifade edici dil olmak üzere genel anlamda iki temel alana ayrıldığı bilinmektedir. Okuma ve dinleme/izleme anlamaya dayalı alıcı dil becerileri, konuşma ve yazma ise anlatıma dayalı ifade edici dil becerilerindendir. Akademik ve işlevsel dil kullanım sürecinde okumanın anlamaya; yazmanın ise anlatıma dayalı dil becerileri içerisinde yer aldığı görülse de bu iki becerinin temelde yazılı dille ilgili beceriler olması ve formal bir eğitime dayanması gibi birtakım benzer özellikleri vardır. Bu benzerliklerden hareketle, okuma ve yazma becerileri arasındaki ilişkinin niteliği çalışmaya zemin hazırlamıştır. Bu bağlamda çalışmanın amacı, ilkokul dördüncü sınıf öğrencilerinin okuma ve yazma becerileri arasındaki ilişkinin incelenmesidir. Araştırmanın çalışma grubunu, 2018-2019 eğitim-öğretim yılı güz döneminde Kayseri il merkezindeki 3 farklı 
ilkokulda öğrenim görmekte olan 141 dördüncü sınıf öğrencisi oluşturmuştur. Çalışma grubunun oluşturulmasında, araştırmaya hız kazandırması açısından kolay ulaşılabilir örnekleme yöntemi kullanılmıştır. Öğrencilerin okuduğunu anlama başarısı ile ilgili verilerin toplanmasında Kocaarslan (2015) tarafından geliştirilen "Okuduğunu Anlama Testi" ve yazılı anlatım becerilerinin değerlendirilmesinde Özkara (2007) tarafından geliştirilen “6+1 Analitik Yazma ve Değerlendirme Ölçeği” kullanılmıştır. Betimsel modelde tasarlanmış korelasyonel (ilişsisel) bir çalışma olan bu araştırmada, ilkokul dördüncü sınıf öğrencilerinin okuma ve yazma becerileri arasındaki ilişkinin belirlenmesinde açıklayıcı ve yordayıcı analizler kullanılmıştır. Veriler, yazma başarısının okuma başarısı tarafından yordanmasına ilişkin olarak basit doğrusal regresyon analizi ve okuma başarısı ile yazma başarısı alt boyutları arasındaki ilişkilerin belirlenmesinde Pearson momentler çarpımı korelasyon katsayısı kullanılarak analiz edilmiştir. Araştırma sonuçlarına göre, okuduğunu anlamanın yazılı anlatım başarısını pozitif yönde yordadığı ve yazma başarısına ilişkin toplam varyansın \%35'inin okuma başarısı ile açıklandığı tespit edilmiştir. Diğer taraftan öğrencilerin yazma başarılarının fikirler, üslup, kelime seçimi, cümle akıcılığı, imla ve sunum boyutlarında okuma başarıları ile pozitif yönde ve orta düzeyde ilişkili olduğu; organizasyon boyutunda ise pozitif yönde ve düşük düzeyde ilişkili olduğu tespit edilmiştir.

Anahtar Kelimeler: Dil Eğitimi, Okuma, Yazma, Okuma ve Yazma İlişkisi, İlkokul Öğrencileri.

\section{Giriş}

İnsanların hayatları boyunca içinde bulundukları iletişim şekilleri ve dil etkinliklerinin başlıca amacı; okuma, dinleme, izleme vasıtasıyla aktarılan herhangi bir iletiyi anlamak ve çevreden gördüğü, duyduğu veya tasarladığı şeyleri açık ve anlaşılır biçimde karşı taraftakine anlatmaktır (Temizkan ve Sallabaş, 2009). İnsanoğlu sahip olduğu bu anlama ve anlatma becerisi sayesinde duygu, düşünce ve isteklerini çevresiyle paylaşma özelliğine sahiptir. Bu beceriler temel dil becerilerinden olup okuma ve dinleme/izleme anlamaya dayalı, konuşma ve yazma ise anlatıma dayalı dil becerilerindendir. Dünyadaki her dil bu dört temel ilkeden oluşur: Ne tür bir dil olduğu, nereden geldiği ve nasıl yapılandırıldığ dinleme becerilerinden oluşur (Yalçınkaya, Muluk ve Şahin, 2009). Sözlü ve yazılı dil gelişiminin tüm yönlerinin (dinleme, konuşma, okuma ve yazma) yakından bağlantılı olduğu ve dil öğreniminin bir alanındaki gelişmenin diğerlerindeki gelişimi etkilediği yaygın olarak kabul edilmektedir (Stone, Silliman, Ehren ve Apel, 2004). Örneğin, bireyin okuduğunu anlama becerisindeki gelişme kelime dağarcığını arttırmakta; bu durum ise çocuğun konuşma ve yazma becerilerini etkileyerek daha iyi yazabilmesi ve konuşabilmesini sağlamaktadır (Sever, 2004).

Dört temel dil becerilerinden okuma ve yazma becerileri, günlük yaşamımız ve akademik başarı için edinilmesi gereken temel dil becerilerindendir. Hem okuma hem de yazma okuryazarlığın bileşenleridir. Bu beceriler bireylerin eğitim hayatını sürdürebilmesi ve çağa uyum sağlayabilmesi için gereklidir (Uğur, 2018). Okuma ve yazma becerileri, öğrencilerin eğitsel, mesleki ve sosyal açıdan başarılı olmak için ustalaşması gereken kritik becerilerden biridir. Öğrencilerin eğitimdeki başarıları, ders kitaplarında ve diğer sınıf materyallerinde sunulan bilgileri okuma ve bu bilgileri eleştirel olarak analiz etme yeteneklerine bağlıdır (Berman, 2009). Yazma becerisi de bireye kendini yazılı olarak ifade etme imkânı verdiği gibi eleştirel düşünme, bilgileri organize etme, yeni fikirler üretme ve planlama gibi beceriler kazandırmaktadır (Kahn ve Holody, 2012).

Akyol'a göre (2016) okuma, uygun bir yönteme ve amaca dayalı olarak düzenli bir ortamda gerçekleştirilen, okuyucu ve yazar arasındaki iletişime dayalı anlamın inşaa edilme sürecidir. Goff, Pratt ve Ong (2005) okumanın, yazılı dilden anlam çıkarmayı içerdiğini ve anlamanın, çocuklara bağımsız okumayı öğretmenin nihai hedefi olduğunu ifade eder. Okuma çeşitli bilişsel ve dilsel süreçlere bağlıdır ve yazılı kelimelerin, cümlelerin ve metinlerin anlamını anlamayı ifade eder. Yine Akyol (2016) okuma ve okunandan anlam kurma becerilerini kazandırmanın, insan hayatını anlamlı hale getirmek amacıyla yapılan en büyük katkı olarak eğitim programlarında ve eğitim öğretim sürecinde yerini aldığını ifade etmiş̧tir. Bir anlatma becerisi olan yazma becerisi ise, zihnimizde 
tasarladığımız duygu, düşünce, istek ve olayların belirli kurallar doğrultusunda bir takım sembollerle aktarılması işlemidir (Güneş, 2013). Yazma becerisi öğrendiklerimizi hatırlamak ve organize etmek için önemli bir araçtır. Hammill (2004), yazma becerisinin çocukların ilerleyen yaşlarda okuduğunu anlama ve okuryazarlık becerilerini doğrudan etkileyeceği için, erken çocukluk döneminden itibaren üzerinde durulması gereken en önemli becerilerden biri olduğunu ifade etmektedir (akt. Tavşanlı ve Yıldırım, 2019). Baştuğ (2012) ise yazmanın, okumayla birlikte öğrencilerde gelişmesi beklenen en önemli dil becerilerinden biri olduğunu ifade etmektedir.

Okuma ve yazma becerilerinin birbirini tamamladığ 1 konusunda genel bir görüş birliği vardır. Bu birliğin, okuma ve yazma becerilerinin temelde yazılı dille ilgili beceriler olması, öğretimlerinin entegre bir biçimde gerçekleștirilmesi ve formal bir eğitime dayanması gibi birtakım benzerliklerden kaynaklandığı söylenebilir. Bu benzerliklerden hareketle okuma ve yazma becerileri arasındaki ilişkiler çeşitli araştırmalara konu olmuştur (Jenkins vd., 2004; Abbott ve Berninger, 1993; Berninger vd., 2002; Loban, 1963; Juel, 1988; Shanahan, 1984; Tierney ve Shanahan, 1991; Uğur, 2018; Juel, Griffith ve Gough, 1986). Okuma ve yazma becerileri arasındaki ilişkileri anlamay1 amaçlayan birçok araştırmanın, her iki becerinin de paylaşılan bilgiye ve bilişsel süreçlere dayandığ teorik bakış açısına dayandığı ifade edilebilir (Andersen vd., 2018). Bu araştırmaların bazıları okuma ve yazma becerileri arasındaki korelasyonları incelerken (Shanahan, 1984) bazıları çok değişkenli yapısal eşitlik modellemesini kullanmıştır (Shanahan ve Lomax, 1986). Yapısal eşitlik modelinde tasarlanmış bir araştırmada ilkokul birinci sınıf öğrencilerinin kelime tanıma, heceleme, okuduğunu anlama ve yazma becerilerinin karşılıklı ilişkisi incelenmiş, okuma ve yazma becerilerinin ilişkili olduğu sonucuna ulaşılmıştır (Juel, Griffith ve Gough, 1986). Yine, Ahmed, Wagner ve Lopez (2014) ilkokul birinci sınıftan dördüncü sınıfa kadar boylamsal bir araștırma ile kelime, cümle ve metin düzeyinde okuma ve yazma becerileri arasındaki ilişkiyi ele almış kelime, cümle ve metin düzeyinde okuma ve yazma becerilerinin ilişkili olduğu ancak, kelime düzeyinde okuma ve yazma becerileri arasındaki ilişkinin, metin ve cümle düzeylerindeki ilişkiden daha güçlü olduğu sonucuna ulaşılmıştır. Çalışmada elde edilen bir başka sonuç ise, çocukların okuma esnasında kullandıkları bilgi tabanını yazılı performanslarına aktardıkları, ancak okuma bilgisini geliştirmek için yazılı anlatım performanslarını kullanamadıklarıdır. Buna karşın çeşitli araştırma sonuçları ise, okuma becerilerine yönelik yapılan müdahalelerin yazma becerilerini veya yazma becerilerine yönelik yapılan müdahalelerin okuma becerilerini geliştirdiğini ifade eder. Andersen ve diğerleri (2018) tarafından ikinci ve üçüncü sınıf öğrencileriyle yapılan araştırmada, kelime, cümle ve metin düzeyinde okuma ve yazma becerilerinin birbirini desteklediği sonucuna ulaşılmıştır. Yine, Graham ve Harris (2017) tarafindan okuma müdahalelerinin yazı üzerindeki etkileri üzerine yapılan bir metaanaliz çalışmasında okuma müdahalelerinin yazma becerilerini güçlendirdiği ve etkilerinin zaman içinde korunduğu sonucuna ulaşılmıştır. Benzer şekilde Graham ve Hebert, (2011) tarafından yazma müdahalelerinin okuma üzerindeki etkileri üzerine yapılan bir meta-analiz çalışmasında yazma becerilerine yönelik yapılan müdahalelerin okuduğunu anlama ve akıcı okuma becerilerini güçlendirdiği sonucuna ulaşılmıştır. Okuma ve yazma becerilerinin ilişkisini ele alan araştırmaların sonuçları genel olarak incelendiğinde, okuma ve yazma becerilerinin ortak bir alana sahip olduğu ancak özdeş beceriler olmadıkları ifade edilebilir.

Diğer taraftan, Williams ve Larkin (2013) küçük çocukların etkili bir yazılı anlatım performansı sergileyebilmeleri için okudukları bir hikâyeden anlam kurmaları gerektiğini ifade etmiştir. Bu ifade çeşitli araştırma sonuçlarıyla da desteklenmiştir (Shanahan, 1984; Abbott, Berninger ve Fayol, 2010; Shanahan ve Lomax, 1986; Juel, 1988). Kim ve diğerleri (2011) tarafindan yapılan araştırmada okuduğunu anlama becerisinin yazılı anlatım performansı ile ilişkili olduğu sonucuna ulaşılmıştır. Bir başka araştırma sonucunda okuduğunu anlama becerisi düşük olan öğrencilerin yazılı anlatım performanslarının da düşük olduğu görülmüş̧ür (Cragg ve Nation, 2006). Yine, Dockrell, Lindsay, Connelly ve Mackie (2007) hem alıc kelime hazinesinin hem de okuma becerisi ölçütlerinin yazılı anlatım performansında önemli faktörler olduklarını ifade etmektedir. 
Buna göre, okuduğunu anlama, akıcı okuma, imlâ, heceleme, kelimeleri tanıma ve fonolojik farkındalık gibi çeşitli okuma bileşenlerinde başarı düzeyi yüksek olan öğrencilerin yazılı anlatım performans düzeylerinin de yüksek olacağ 1 söylenebilir.

Görüldüğü üzere, okuma ve yazma becerilerinin ilişkisini ele alan gerek kuramsal gerekse tarama, betimsel ve müdahaleli araştırmaların yurtdışında oldukça fazla olmasına karşın yurtiçinde doğrudan bu ilişkiyi ele alan sınırlı sayıda olması (örn. Uğur, 2017) ayrıca okuma ve yazma gibi temel dil becerileri arasındaki ilişkinin özellikle ilkokul seviyesinde incelenmesi gerektiği araştırmamızın çıkış noktasını oluşturmuştur. $\mathrm{Bu}$ nedenle araştırmamızda, ilkokul 4. sınıf öğrencilerinin okuma ve yazma becerileri arasındaki ilişkinin incelenmesi amaçlanmıştır. $\mathrm{Bu}$ amaç çerçevesinde aşağıdaki araştırma sorusuna cevap aranmıştır:

1. İlkokul 4. sınıf öğrencilerinin okuduğunu anlama becerisi yazılı anlatım becerilerinin anlamlı yordayıcisı midir?

2. İlkokul 4. sınıf öğrencilerinin okuduğunu anlama becerileri ile yazma becerileri alt boyutları arasında anlamlı ilişkiler var mıdır?

\section{Yöntem}

\section{Araștırmanın Yöntemi}

İki ya da daha çok değişken arasındaki ilişkinin herhangi bir şekilde bu değişkenlere müdahale edilmeden incelendiği araştırmalara korelasyonel araştırmalar denir (Neuman, 2006). Bu araştırma, ilkokul 4. sınıf öğrencilerinin okuma ve yazma becerileri arasındaki ilişkiyi incelemesi nedeniyle betimsel modelde tasarlanmış korelasyonel bir araştırmadır.

\section{Çalışma Grubu}

Araştırmanın çalışma grubunu, 2018-2019 eğitim-öğretim yılı güz döneminde Kayseri ilinde bulunan ilkokullardan 77'si kız, 64'ü erkek olmak üzere 141 dördüncü sınıf öğrencisi oluşturmuştur. Çalışma grubunun oluşturulmasında araştırmanın amacına uygun olarak kolay ulaşılabilir örnekleme yöntemi kullanılmıştır.

\section{Veri Toplama Araçları}

Veriler Kocaarslan (2015) tarafindan geliştirilen "Okuduğunu Anlama Testi (OAT)" ve Özkara (2007) tarafindan Türkçeye uyarlanan "6+1 Analitik Yazma ve Değerlendirme Ölçeği (6+1 AYDÖ)" kullanılarak toplanmıştır.

\section{Okuduğunu Anlama Testi (OAT)}

Kocaarslan (2015) tarafından geliştirilen okuduğunu anlama testi öyküleyici ve bilgilendirici olmak üzere iki metinden oluşmaktadır. Her bir metin için basit ve derin anlamaya yönelik 10 soru bulunmaktadır.

$\mathrm{Bu}$ araştırmada okuduğunu anlama testinin öyküleyici metni ve bu metne bağl1 10 açık uçlu soru kullanılmıştır. Açık uçlu sorulara verilen cevapların standart puanlara dönüştürülmesinde, Akyol (2011) tarafindan önerilen Tablo 1'deki yol izlenmişsir. 
Tablo 1. Açık Uçlu Sorulara Ait Cevapların Puanlanması

\begin{tabular}{ll}
\hline $\begin{array}{l}\text { Basit Anlamaya Dayalı Soruları için Puanlama } \\
\text { sistemi }\end{array}$ & $\begin{array}{l}\text { Derin Anlamaya Dayalı Soruları İçin Puanlama } \\
\text { Sistemi }\end{array}$ \\
\hline $0=$ Hiç Cevaplanmayan Sorular & $0=$ Hiç Cevap Verilmeyen Sorular \\
$1=$ Yarı Cevaplanan Sorular & $1=$ Yarı Cevap Verilen Sorular \\
$2=$ Tam Cevaplanan Sorular & $2=$ Beklenen Ancak Eksik Olan Cevaplar \\
& $3=$ Tam ve Etkili Cevaplar \\
\hline
\end{tabular}

\section{6+1 Analitik Yazma ve Değerlendirme Ölçeği (6+1 AYDÖ)}

Özkara (2007) tarafından Türkçeye uyarlanan ölçek, nitelikli bir yazının sahip olması gereken özellikleri fikirler, organizasyon, üslûp, kelime seçimi, cümle akıcıllğ 1 , imlâ ve sunum olarak yedi başlık altında toplamıştır. Yazılı anlatım verileri bu yedi başlık göz önünde bulundurularak araştırmacılar tarafından 1,3 ve 5 şeklinde puanlandırılmıştır. Ölçekten alınabilecek en düşük puan 7 , en yüksek puan ise $35^{\prime}$ dir.

Sarikaya ve Yılar (2018) tarafından yapılan çalışmada ölçeğin tamamına yönelik Cronbach alfa güvenirlik katsayıs1 .95 , puanlayıcılar arası uyum indeksi .90 ve Spearman Brown iki yarı test güvenirlik katsayısı .93 olarak bulunmuştur. Veriler ölçeğin geçerli güvenilir bir araç olduğunu göstermektedir.

\section{Verilerin Toplanması}

Veri toplama sürecine, öncelikle yazılı anlatım verilerinin toplanmasıyla başlanmıştır. Yazılı anlatım verilerinin toplanması için öğrencilerden üç alan uzmanı tarafindan belirlenen "Ailesiyle lunaparka giden bir çocuğun yaşadıklarını anlatan bir hikâye yazınız."; "Soğuk bir kış gününde sokakta kalmış küçük bir köpeğin başından geçen olayları anlatan bir hikâye yazınız."; "Okula yeni başlayan bir çocuğun başından geçen olayları anlatan bir hikâye yazınız."; "Ormanda yolunu kaybetmiş küçük maymunun başından geçen olayları anlatan bir hikâye yazınız." dört konudan herhangi birini seçerek bir hikâye yazmaları istenmiştir. Yazılı anlatım verileri her sınıfta bir ders saati içerisinde toplanmıştır. Hikâye yazma süreci tamamlandıktan sonra okuduğunu anlama verilerinin toplanması için öğrencilere okuduğunu anlama testi uygulanmıştır. Testin uygulanması her bir sınıfta iki ders saati sürmüş̧ür. İlk ders saatinde öğrencilere test hakkında bilgi verilerek "İyilik" başlıklı metin sınıfta bir kez sessiz ve bir kez sesli olmak üzere okutulmuştur. İkinci ders saatinde ise okuduğunu anlama testine yönelik sorular öğrenciler tarafından cevaplanmıştır.

\section{Verilerin Analizi}

Araştırmada toplanan veriler SPSS-20.0 programı kullanılarak çözümlenmiştir. İlk olarak verilerin normal dağılım gösterip göstermediği incelenmiştir. Can (2016) verilerin normal dağılım özelliklerinin sınanması için farklı yolların bulunduğunu, verilerin çarpıklık ve basıklık katsayılarına bakılarak normallik kontrolü yapılacağını ifade etmektedir. Verilerin dağılımının normal olup olmadığını belirlemek amacıyla okuma başarısı $(-.010 ;-.201)$ ve yazma başarısı $(-.095 ;-.059)$ için sırasıyla çarpıklık (skewness) ve basıklık (kurtosis) değerlerine bakılmıştır. Hem çarpıklık hem de basıklık değerlerinin +1,500 ile -1,500 değerleri arasında (Tabachnick ve Fidell, 2013) olduğu, bu nedenle normal dağılım gösterdiği tespit edilmiştir.

Veriler, yazma başarısının okuma başarısı tarafından yordanmasına ilişkin olarak "Basit Doğrusal Regresyon Analizi" kullanılarak; okuma başarısı ile yazma başarısı alt boyutları arasındaki ilişkilerin belirlenmesine ilişkin olarak ise "Pearson Momentler Çarpımı Korelasyon Katsayısı" kullanılarak analiz edilmiştir. 


\section{Bulgular ve Yorum}

Araştırmanın birinci alt problemi "İlkokul 4. sınıf öğrencilerinin okuduğunu anlama becerileri yazma becerilerinin anlamlı yordayıcısı mıdır?" olarak belirtilmiştir. Bu alt probleme yönelik olarak yapılan Basit Regresyon Analizi sonuçları Tablo 2'de verilmiştir.

Tablo 2. Yazma Becerisinin Yordanmasına İlişkin Basit Regresyon Analizi Sonuçları

\begin{tabular}{cccccccc}
\hline Değişken & B & $\begin{array}{c}\text { Standart } \\
\text { hata }\end{array}$ & $\boldsymbol{B}$ & $\boldsymbol{T}$ & $\boldsymbol{P}$ & İkili r & Kısmi R \\
\hline Sabit & 3.774 & 0.510 & - & 7.394 & .000 & - & - \\
\hline $\begin{array}{l}\text { Okuduğunu } \\
\text { Anlama }\end{array}$ & .209 & 0.024 & 0.594 & 8.709 & .000 & 0.594 & 0.594 \\
$\quad$ & & & & & & \\
Becerisi & & & & & & & \\
\hline $\begin{array}{l}R=0.594, \quad R^{2}=0.35 \\
F(1,139)=75,854, \quad p=.000\end{array}$ & & & & & & \\
\hline
\end{tabular}

Araştırma sonuçlarına göre, okuduğunu anlama başarısının yazma başarısını pozitif yönde yordadı $\breve{g} 1(\mathrm{R}=0.594, \mathrm{R} 2=0.35, \mathrm{~F}(1,139)=75,854, \mathrm{p}<.01)$ ve yazma başarısına ilişkin toplam varyansın \%35'inin okuduğunu anlama başarısı ile açıklandığı tespit edilmiştir. eşitliği;

Regresyon analizi sonuçlarına göre yazma becerisinin yordanmasına ilişkin regresyon

\section{YAZMA BECERİSİ=3.774+0.209OKUDUĞUNU ANLAMA BECERİSİ}

Araştırmanın ikinci alt problemi "İlkokul 4. sınıf öğrencilerinin okuduğunu anlama becerileri ile yazma becerileri alt boyutları arasında anlamlı ilişkiler var mıdır?" olarak belirtilmiştir. Bu alt probleme yönelik olarak yapılan Pearson Korelasyon testi sonuçları Tablo 3'de verilmiştir.

Tablo 3. Öğrencilerin Okuduğunu Anlama Becerisi ile Yazma Becerileri Alt Boyutları Arasındaki Korelasyon Sonuçları

\begin{tabular}{|c|c|c|c|c|c|c|c|c|}
\hline Değişkenler & 1 & 2 & 3 & 4 & 5 & 6 & 7 & 8 \\
\hline $\begin{array}{l}\text { 1.Okuduğunu } \\
\text { Anlama Becerisi }\end{array}$ & - & & & & & & & \\
\hline 2.Fikirler & $.423 * *$ & - & & & & & & \\
\hline 3.Organizasyon & $.260 * *$ & $.597 * *$ & - & & & & & \\
\hline 4.Üslup & $.465 * *$ & $.445 * *$ & $.397 * *$ & - & & & & \\
\hline 5.Kelime Seçimi & $.356^{* *}$ & $.372 * *$ & $.329 * *$ & $.404 * *$ & - & & & \\
\hline 6.Cümle Akıcılığı & $.440 * *$ & $.465^{* *}$ & $.571 * *$ & $.546^{* *}$ & $.436^{* *}$ & - & & \\
\hline 7.İmla & $.498^{* *}$ & $.395^{* *}$ & $.358 * *$ & $.360 * *$ & $.319 * *$ & $.437 * *$ & - & \\
\hline 8.Sunum & $.461 * *$ & $.357 * *$ & $.241 * *$ & $.356^{* *}$ & $.264 * *$ & $.306^{* *}$ & $.507 * *$ & - \\
\hline
\end{tabular}

Tablo 3'e göre, öğrencilerin yazma başarılarının, fikirler ( $\mathrm{r}=0.423, \mathrm{p}<.01)$, üslup $(\mathrm{r}=0.465$, $\mathrm{p}<.01)$, kelime seçimi $(\mathrm{r}=0.356, \mathrm{p}<.01)$, cümle akıc1lı̆̆ $(\mathrm{r}=0.440, \mathrm{p}<.01)$, imla $(\mathrm{r}=0.498, \mathrm{p}<.01)$ ve sunum $(\mathrm{r}=0.461, \mathrm{p}<.01)$ boyutlarında okuduğunu anlama başarıları ile pozitif yönde ve orta düzeyde 
ilişkili olduğu; organizasyon $(r=0.260, \mathrm{p}<.01)$ boyutunda ise pozitif yönde ve düşük düzeyde ilişkili olduğu tespit edilmiştir.

\section{Sonuç, Tartışma ve Öneriler}

Araştırma sonuçlarına göre, okuduğunu anlama başarısının yazma başarısını pozitif yönde yordadığı yazma başarısına ilişkin toplam varyansın \%35'inin okuma başarısı ile açıklandığı tespit edilmiştir. Diğer taraftan öğrencilerin yazma başarılarının, fikirler, üslup, kelime seçimi, cümle akıcılı̆̆ı, imla ve sunum boyutlarında okuma başarıları ile pozitif yönde ve orta düzeyde ilişkili olduğu; organizasyon boyutunda ise pozitif yönde ve düşük düzeyde ilişkili olduğu tespit edilmiştir.

İlgili literatür incelendiğinde, okuduğunu anlama becerisi ile yazma becerisinin birbiriyle ilişkili olduğunu gösteren birçok çalışma bulunmaktadır (Adams, 1990; Abbott ve Berninger, 1993; Ahmed, Kim ve Wagner, 2014; Carson, Carrell, Silberstein, Kroll ve Kuehn, 1990; Baştuğ, 2012; Berninger vd., 2002; Genlott, ve Grönlund, 2013; Hinkson, 1998; Jenkins vd., 2004; Juel, 1988; Juel, Griffith ve Gough, 1986; Lin ve Siriyothin, 2008; Loban, 1963; Nelson, 2003; Parodi, 2007; Palmer, 2010; Pugh vd., 2006; Scott, 2009; Shanahan, 1984; Tierney ve Shanahan, 1991; Uğur, 2018). Diğer taraftan, bazı kuramsal çalışmalar da okuma ve yazma becerileri arasında ilişki olduğunu destekler niteliktedir (Berninger vd., 2002; Fitzgerald ve Shanahan, 2000; Jenkins vd., 2004). Bu ilişki bazı çalışmalarda yüksek düzeyde olmasına rağmen (Koons, 2008; Scott, 2009) bazı çalışmalarda orta düzeydedir (Uğur, 2018). Okuma ve yazma becerileri arasında her zaman yüksek düzeyde olmasa da pozitif yönde bir ilişkinin olduğu, dolayısıyla okuma ve yazma becerilerinin birbirini bütünleştirdiği ve birinin diğerinden ayrı düşünülemeyeceği ifade edilebilir.

Palmer (2010) 18'i deney, 36'sı kontrol grubu olmak üzere 54 üçüncü sınıf öğrencisiyle yürüttüğü araştırmada öğrencilerin okuma akıcıllğı, yazma akıcılı̆̆ 1 ve okuduğunu anlama düzeyleri arasındaki ilişkiyi belirlemeyi amaçlamıştır. Araştırma sonucuna göre, okuduğunu anlama ve okuma akıc1lığ , okuduğunu anlama ve yazma akıc1lığ yönlü güçlü ilişkilerin olduğu saptanmıştır. Bu sonuca göre okuduğunu anlama, akıcı okuma ve akıcı yazma becerilerinden herhangi birinde gelişme gösteren öğrencilerin diğer becerilerinin de gelişeceği söylenebilir. Benzer bir çalışmayı ise Uğur (2018) ortaokul 7. sınıf öğrencileriyle gerçekleştirmiştir. Öğrencilerin okuduğunu anlama ve yazma başarıları arasındaki ilişkinin incelendiği çalışmanın sonucuna göre okuduğunu anlama becerisi ile yazma becerisi arasında pozitif yönde orta düzeyde bir ilişki bulunmuştur. Orta düzeyde bir ilişkinin bulunmasının sebeplerini ise öğrencilerin bahsi geçen becerilerinin geliştirilmesine yönelik eğitim geçmişlerinin farklı olmasına, becerilere yönelik tutumlarının farklı olmasına, veri toplama sürecinde bir kısım öğrencilerin gerçek performanslarını ortaya koyamamış olmalarına dayandırmıştır. Aynı şekilde Nelson (2003) 105 öğrenciyle gerçekleştirmiş olduğu çalışmasında okuma, yazma ve anlama becerileri arasında ilişkinin olduğu sonucuna ulaşmıştır. Diğer taraftan doğru okuma ve akıcı okumanın sözlü ve yazılı anlamaya önemli katkılarının olduğu saptanmıştır. Baştuğ (2012) ise çalışmasında okuduğunu anlama, yazma ve akıcı okuma becerileri arasındaki ilişkiyi incelemiştir. Her sınıf düzeyinden 18 öğrenci olmak üzere ilkokul 2 ve 5 arası sınıflardan 72 öğrenci ile gerçekleştirilen araştırmanın sonucuna göre, öğrencilerin okuduğunu anlama ve yazma becerileri arasında yüksek düzeyde ve pozitif yönde ilişki bulunmuştur $(\mathrm{r}=.775)$. Son olarak okuma ve yazma becerileri arasındaki ilişkiyi Shanahan (1984) okuma becerisi için okumanın temelinde yer alan kelime bilgisi, kelimeyi tanıma, cümleyi ve metni anlama; yazma becerisi için ise yazılı anlatımın temelinde yer alan kelime çeşitliliği, cümle karmaşıklığı, yazım ve organizasyon gibi çeşitli ölçütlerle incelemiştir. Çalışmanın sonuçlarına göre okuma ve yazma becerilerinin ilişkili olduğu saptanmıştır.

Çalışmamıza paralel olarak yapılan yukarıdaki çalışmalar ve konuyla ilgili literatürdeki diğer çalışmalar bir bütün olarak incelendiğinde, çeşitli eğitim düzeylerindeki öğrencilerin okuma ve yazma becerileri arasında pozitif yönlü bir ilişkinin bulunduğu söylenebilir. Dğer taraftan, bu araştırmada okuma başarısının yazma başarısını pozitif yönde yordadığı sonucundan yola çıkarak, 
okuma ve yazma becerilerinin etkileşimine yönelik farklı araştırmalar da yürütülebilir. Yürütülecek araştırmalarda okuma ve yazmanın alt boyutları arasındaki ilişkiler değerlendirilebilir. Ayrıca okuma ve yazma becerileri arasındaki ilişkiye duyuşsal faktörlerin etkisi araştırılabilir. Yerli literatürde bu konuda yapılan çalışmaların azlığı göze çarpmakta olup farklı çalışma gruplarıyla, farklı bağlamlarda ve farklı yöntemlerle çalışılması önerilmektedir.

\section{Kaynakça}

Abbott, R. D., \& Berninger, V. W. (1993). Structural equation modeling of relationships among developmental skills and writing skills in primaryand intermediate-grade writers. Journal of Educational Psychology, 85, 478-508. https://doi.org/10.1037/0022-0663.85.3.478

Abbott, R. D., Berninger, V. W., \& Fayol, M. (2010). Longitudinal relationships of levels of language in writing and between writing and reading in grades 1 to 7 . Journal of educational psychology, 102(2), 281. https://doi.org/10.1037/a0019318

Adams, M. J. (1990). Beginning to read: Thinking and learning about print. Cambridge, MA: MIT Press.

Akyol, H. (2006). Yeni programa uygun Türkçe ögretim yöntemleri. Kök Yayınc1lık. https://doi.org/10.14527/9786053640011

Akyol, H. (2016). Programa uygun türkçe öğretim yöntemleri. Pegem Akademi Yayıncılık. https://doi.org/10.14527/9786053640011

Ahmed, Y., Kim, Y.-S., \& Wagner, R. K. (2014). Why we should care about literacy models: Models of reading and writing and how they can elucidate the connection between reading and writing. In B. Miller, P. McCardle \& R. Long (Eds.), Teaching reading and writing improving instruction and student achievement (pp. 143-152). Baltimore, Maryland: Brooks. https://doi.org/10.4324/9780429490767-21

Ahmed, Y., Wagner, R. K., \& Lopez, D. (2014). Developmental relations between reading and writing at the word, sentence, and text levels: A latent change score analysis. Journal of Educational Psychology, 106(2), 419-434. https://doi.org/10.1037/a0035692

Andersen, S. C., Christensen, M. V., Nielsen, H. S., Thomsen, M. K., Østerbye, T., \& Rowe, M. L. (2018). How reading and writing support each other across a school year in primary school children. Contemporary Educational Psychology, 55, 129-138. https://doi.org/10.1016/j.cedpsych.2018.09.005

Baştuğ, M. (2012). İlköğretim I. kademe öğrencilerinin akıcı okuma becerilerinin çeşitli değişkenler açısından incelenmesi. Doktora tezi, Gazi Üniversitesi Eğitim Bilimleri Enstitüsü, Ankara. https://doi.org/10.17679/inuefd.323135

Berman, I. (2009). Supporting adolescent literacy achievement. Issue Brief, Issue Brief. NGA Center for Best Practices, 1-15.

Berninger, V. W., Abbott, R. D., Abbott, S. P., Graham, S., \& Richards, T. (2002). Writing and reading: Connections between language by hand and language by eye. Journal of Learning Disabilities, 35, 39-56. https://doi.org/10.1177/002221940203500104

Can, A. (2016). Bilimsel araştırma sürecinde SPSS ile nicel veri analizi. Pegem Akademi Yayınc1lık. https://doi.org/10.14527/9786053644484

Carson, E. J., Carrell, P. L., Silberstein, S., Kroll, B., \& Kuehn, P. A. (1990). Reading-writing relationships in frst and second language. TESOL Quarterly, 24(2), 245-266. https://doi.org/10.2307/3586901 
Cragg, L., \& Nation, K. (2006). Exploring written narrative in children with poor reading comprehension. Educational Psychology, 26(1), 55-72. https://doi.org/10.1080/01443410500340991

Dockrell, J. E., Lindsay, G., Connelly, V., \& Mackie, C. (2007). Constraints in the production of written text in children with specific language impairments. Exceptional Children, 73, 147164. https://doi.org/10.1177/001440290707300202

Fitzgerald, J., \& Shanahan, T. (2000). Reading and writing relations and their development. Educational Psychologist, 35(1), 39-50. https://doi.org/10.1207/s15326985ep3501_5

Genlott, A. A., \& Grönlund, Å. (2013). Improving literacy skills through learning reading by writing: The iWTR method presented and tested. Computers \& Education, 67, 98-104. https://doi.org/10.1016/j.compedu.2013.03.007

Goff, D. A., Pratt, C., \& Ong, B. (2005). The relations between children's reading comprehension, working memory, language skills and components of reading decoding in a normal sample. Reading and Writing, 18, 583-616. https://doi.org/10.1007/s11145-004-7109-0

Graham, S., \& Harris, K. R. (2017). Reading and writing connections: How writing can build better readers (and Vice Versa). In C. Ng \& B. Bartlett (Eds.), Improving reading and reading engagement in the 21st century (pp. 333-350). Singapore: Springer. https://doi.org/10.1007/978-981-10-4331-4_15

Graham, S., \& Hebert, M. (2011). Writing to read: A meta-analysis of the impact of writing and writing instruction on reading. Harvard Educational Review, 81(4), 710-744. https://doi.org/10.17763/haer.81.4.t2k0m13756113566

Güneş, F. (2013). Türkçe öğretimi yaklaşımlar ve modeller. Pegem Akademi Yayıncılık. https://doi.org/10.14527/9786053644927

Hinkson, J. (1998). The impact of telecommunications on writing skills and reading comprehension in at-risk elementary students. Doctoral Dissertation, Southern California University.

Jenkins, J. R., Johnson, E., \& Hileman, J. (2004). When is reading also writing: Sources of individual differences on the new reading performance assessments. Scientific Studies of Reading, 8, 125-151. https://doi.org/10.1207/s1532799xssr0802_2

Juel, C. (1988). Learning to read and write: A longitudinal study of 54 children from first through fourth grades. Journal of Educational Psychology, 80, 437-447. https://doi.org/10.1037/0022-0663.80.4.437

Juel, C., Griffith, P., \& Gough, P. (1986). Acquisition of literacy: A longitudinal study of children in first and second grade. Journal of Educational Psychology, 78, 243-255. https://doi.org/10.1037/0022-0663.78.4.243

Kahn, J. M., \& Holody, R. (2012). Supporting field instructors' efforts to help students improve writing. Journal of Social Work Education, 48(1), 65-73. https://doi.org/10.5175/jswe.2012.201000018

Kim, Y., Al Otaiba, S., Puranik, C., Folsom, J. S., Greulich, L., \& Wagner, R. K. (2011). Componential skills of beginning writing: An exploratory study. Learning and Individual Differences, 21(5), 517-525. https://doi.org/10.1016/j.lindif.2011.06.004

Kocaarslan, M. (2015). Zihinsel imaj oluşturma öğretiminin 4. slnıf ögrencilerinin okuduğunu anlama becerilerini geliştirmeye etkisi. Doktora Tezi, Gazi Üniversitesi Eğitim Bilimleri Enstitüsü, Ankara. https://doi.org/10.16986/huje.2016016670 
Koons, H. H. (2008). The reading-writing connection: An investigation of the relationship between reading ability and writing quality across multiple grades and three writing discourse modes. Doctoral Dissertation, University of North Carolina.

Lin, Z., \& Siriyothin, P. (2008). Effects of reading tasks on reading comprehension of Chinese EFL students: A pilot study, US-China Foreign Language, 6(5), 12-19.

Loban, W. D. (1963). The language of elementary school children. Urbana, IL: National Council of Teachers of English.

Nelson, D. (2003). Relationships among reading, writing, and comprehension skills of intermediate elementary school. Doctoral Dissertation, Maryland University.

Neuman, W. L. (2006). Toplumsal araştırma yöntemleri, nitel ve nicel yaklaşımlar (Ö. Sedef, Çev.). Yayınodası Yayıncılık.

Özkara, Y. (2007). 6+1 analitik yazma ve değerlendirme modelinin 5. sinı öğrencilerinin hikâye edici metin yazma becerilerini geliştirmeye etkisi. Doktora Tezi, Gazi Üniversitesi Eğitim Bilimleri Enstitüsü, Ankara. https://doi.org/10.14686/buefad.2015usosozelsayi13212

Parodi, G. (2007). Reading-writing connections: Discourse-oriented research. Reading and Writing, 20, 225-250. https://doi.org/10.1007/s11145-006-9029-7

Palmer, M. L. (2010). The relationship between reading fluency, writing fluency and reading comprehension in suburban third-grade students. Doctoral Dissertation, University Of San Diego.

Pugh, K. R., Frost, S. J., Sandak, R., Gillis, M., Moore, D., Jenner, A. R., \& Mencl, W. E. (2006). What does reading have to tell us about writing? Preliminary question and methodological challenges in examining the neurobiological foundations of writing and writing disabilities. In C. A. MacArthur, S. Graham, \& J. Fitzgerald (Eds.), Handbook of writing research (pp. 433-448). New York, NY: Guilford. https://doi.org/10.1007/s11145-008-9121-2

Sarikaya, İ., \& Yılar, Ö. (2018). 6+1 analitik yazma ve değerlendirme ölçeğinin uyarlanması: Güvenirlik ve geçerlik çalıșması. 27. Uluslararası Ĕ̈itim Bilimleri Kongresi: Değișen Dünyada Eğitim içinde, 497-503. https://doi.org/10.1501/egifak_0000001314

Sever, S, (2004). Türkçe ögretimi ve tam öğrenme. Anı Yayıncılık.

Scott, J.R. (2009). A quantitative study on the relationship between fifth grade students' reading and writing test scores. Education Specialist in Elementary Education Thesis, Troy University.

Shanahan, T. (1984). Nature of reading-writing relations: An exploratory multivariate analysis. Journal of Educational Psychology, 76, 466-477. https://doi.org/10.1037/00220663.76.3.466

Shanahan, T., \& Lomax, D. (1986). An analysis and comparison of theoretical models of readingwriting relationship Journal of Educational Psychology, 78, 116-123. https://doi.org/10.1037/0022-0663.78.2.116

Stone, C. A., Silliman, E. R., Ehren, B. J., \& Apel, K. (Ed.). (2004). Handbook of language and literacy. NewYork: The Guilford.

Tabachnick, B.G., \& Fidell. L.S. (2013). Using multivariate statistics (sixth ed.). Boston: Pearson.

Tavşanlı, Ö. F., Bilgin, A., ve Yıldırım, K. (2019). Yazmaya İlişkin Tutum Ölçeğinin Türkçe Uyarlama Çalışmaları. Dil Eğitimi ve Araştırmaları Dergisi, 5(2), 267-282. https://doi.org/10.31464/jlere.561205 
Temizkan, M., \& Sallabaş, M. E. (2009). Öğretmen adaylarının okuma ve yazmaya yönelik tutumlarının karşılaştırılması. Elektronik Sosyal Bilimler Dergisi, 8(27), 155-176. https://doi.org/10.12780/uusbd281

Tierney, R. J., \& Shanahan, T. (1991). Research on the reading-writing relationship: Interactions, transactions, and outcomes. In R. Barr, M. L. Kamil, P. B. Mosenthal, \& P. D. Pearson (Eds.), Handbook of reading research (Vol. 2, pp. 246-280). Hillsdale, NJ: Erlbaum.

Uğur, F. (2017). Ortaokul 7. sınıf öğrencilerinin bilgilendirici metin yapısı unsurlarını belirleme düzeyleri. Mustafa Kemal Üniversitesi Sosyal Bilimler Enstitüsü Dergisi, 14(39), 220-222. https://doi.org/10.18506/anemon.520992

Uğur, F., (2018). Ortaokul 7. sınıf öğrencilerinin okuduğunu anlama ve yazma başarıları arasındaki ilişki. Okuma Yazma Eğitimi Araştırmaları, 6(1), 1-12. https://doi.org/10.35233/oyea.571160

Yalçınkaya, F., Muluk, N. B., \& Şahin, S. (2009). Effects of listening ability on speaking, writing and reading skills of children who were suspected of auditory processing difficulty. International journal of pediatric otorhinolaryngology, 73(8), 1137-1142. https://doi.org/10.1016/j.ijporl.2009.04.022

Yurdugül, H. (2005). Ölçek geliştirme çalışmalarında kapsam geçerliği için kapsam geçerlik indekslerinin kullanılması. XIV. Ulusal Eğitim Bilimleri Kongresi, 1, 771-774. https://doi.org/10.17556/erziefd.297741

Williams, G. J., \& Larkin, R. F. (2013). Narrative writing, reading and cognitive processes in middle childhood: What are the links? Learning and Individual Differences, 28, 142-150. https://doi.org/10.1016/j.lindif.2012.08.003 